Canadian

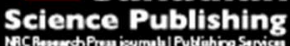

Applied Physiology, Nutrition, and Metabolism Physiologie appliquée, nutrition et métabolisme

\title{
Impact of CIHR Reforms on the Funding of Nutritional Sciences in Canada
}

\begin{tabular}{|r|l|}
\hline Journal: & Applied Physiology, Nutrition, and Metabolism \\
\hline Manuscript ID & apnm-2016-0532 \\
\hline Manuscript Type: & Discussion \\
\hline Complete List of Authors: & $\begin{array}{l}\text { Ma, David; University of Guelph, } \\
\text { Bertolo, Robert; Memorial University of Newfoundland, Department of } \\
\text { Biochemistry; } \\
\text { Robbins, Sarah; Kelowna General Hospital } \\
\text { Marchand, Valerie; Universite de Montreal } \\
\text { Duncan, Alison; University of Guelph, } \\
\text { Plourde, Melanie; Universit } \curvearrowright \text { de Sherbrooke } \\
\text { Grantham, Andrea; Canadian Nutrition Society }\end{array}$ \\
\hline Keyword: & \begin{tabular}{l} 
nutrition, CIHR, research funding \\
\hline
\end{tabular} \\
\hline
\end{tabular}


Discussion of "Impact of CIHR Reforms on the Funding of Nutritional Sciences in Canada"

David W.L. Ma*, Robert F. Bertolo, Sarah Robbins, Valerie Marchand, Alison M. Duncan, Melanie Plourde and Andrea Grantham

Dr. David W.L. Ma, Vice President Research and President Elect, CNS

Dr. Robert F. Bertolo, Past President, CNS

Dr. Sarah Robbins, President, CNS

Dr. Valerie Marchand, Vice President Clinical, CNS

Dr. Alison M. Duncan, Treasurer, CNS

Dr. Melanie Plourde, Member at Large, CNS

Andrea Grantham, Executive Director, CNS

*Corresponding Author: David W.L. Ma, Ph.D.

Dept. of Human Health and Nutritional Sciences

Animal Science/Nutrition Building, Rm 342

491 Gordon Street

College of Biological Science, University of Guelph

Guelph, Ontario Canada N1G 2W1

Phone: 519-824-4120, ext 52272

Email: davidma@uoguelph.ca 
There has been widespread reporting on the recent Canadian Institutes of Health Research (CIHR) Project scheme results and challenges. Much credit goes to Dr. Jim Woodgett, whose efforts have led to a 'protest' by Canadian researchers which has resulted in a partial reversal of the peer review reforms introduced by CIHR. The resultant CIHR 'Peer Review Working Group' has been urgently working to fix the peer review process and renew our faith in publicly funded health research in Canada. Many tragic accounts were reported in social media and stories in the public press complaining about the review process. There has also been anecdotal speculation about the dire impact the reforms had within specific disciplines. To assess the impact on the field of nutrition, the Canadian Nutrition Society (CNS) sought to gather specific insight by conducting two member surveys of the results and experiences of applicants and reviewers from the recent Project and Foundation scheme competitions. The surveys confirmed what many speculated and also revealed some additional startling insights. Due to the sheer number of applicants, the Project Scheme competition received most of the attention, but similar concerns were noted in the Foundation Scheme. A summary of key findings is listed below:

Principal Investigator (PI) Survey:

- The survey captured 42 Project Scheme grants submitted by 32 PIs. $67 \%$ of these grants ranked below the $50^{\text {th }}$ percentile, $90 \%$ below the $75^{\text {th }}$ percentile. One grant was fully funded which indicates a $2 \%$ success rate, well below the overall success rate of $13 \%$.

- Two applicants received bridge funding.

- Eight respondents applied for Foundation funding. All eight applicants received scores below the $75^{\text {th }}$ percentile and none were funded. 
- For both Project and Foundation grants, 93\% of respondents indicated that they were not provided with high quality reviews. Further, $96 \%$ of respondents indicated that they believed that reviewers lacked the necessary expertise to review their grants. There was also the perception that grants were not discussed amongst the other reviewers.

\section{Reviewer Survey:}

- The survey revealed that the matching process used to identify potential reviewers was not successful in reaching out to all eligible nutrition reviewers. Among the 31 respondents that had previously reviewed for Tri-council funding, only 17 (54\%) received invitations to review for the Project Scheme competition.

- Reviewers who were invited and accepted were asked to review grants outside of their nutrition focus; only $37 \%$ indicated that the majority of their assigned grants had a nutrition focus.

- Only 5/27 respondents were invited to review for the Foundation Scheme competition.

- While we have heard anecdotal feedback that CIHR had difficulty identifying potential reviewers, our findings indicate that many potential nutrition reviewers were not contacted. Of the 14 respondents who indicated that they were not asked to be a reviewer, $79 \%(11 / 14)$ indicated that they would have agreed to participate. Some respondents indicated that they declined the opportunity because the grants that they were sent were outside of their area of expertise.

The PI and reviewer experiences were not unlike those reported by many others in social and print media articulating a very negative experience. While the consensus has been that reviewers 
lacked the necessary expertise or grants were poorly matched to reviewers, our survey results uniquely highlight a negative bias towards nutrition as a discipline. Given the obvious importance of nutrition for health and disease, it is extremely concerning that some reviewers had overtly questioned even the 'need' for nutrition research. This reviewer bias contributed to an already dire situation due to a new system that has significantly reduced the funding success of nutrition grants that historically had a $15-20 \%$ success through the Nutrition, Food and Health peer review committee.

The CNS has openly shared these findings with key leaders within CIHR to make a strong case for reforms that will help to improve the future success of the nutrition community. Further, the CNS is formally requesting that CIHR implement the following changes in time for future competitions:

1. CIHR must fulfill its recent commitment to reinstate face-to-face reviews to ensure appropriate review and discussions take place among reliable (and accountable) reviewers.

2. Processes must be put in place to recruit reviewers with nutrition expertise and to appropriately match these reviewers to nutrition grants.

3. CIHR must recognize nutrition as a health discipline in itself, rather than as a category underneath various disease states. Protected (discipline) funding for nutrition grants must be enabled by allowing a nutrition committee or cluster to review nutrition grants in the new review model. 
The case for supporting nutrition research in Canada is many-fold. The enormous healthcare spending on largely preventable chronic diseases in all major countries, including Canada, is well documented. These issues have reached epidemic proportions costing billions in direct and indirect costs to the Canadian healthcare system and many years of lost productivity, reduced quality of life and years of life expectancy. Canada has taken some steps in an attempt to address these issues. Nutrition is identified as a fundamental discipline within the CIHR - Institute of Nutrition, Metabolism and Diabetes (INMD) where "Food and Health" has been identified as a strategic priority. Similarly, the Minister of Health Mandate letter has identified several key nutrition priorities to be addressed in the next few years, including bringing in tougher regulations to eliminate trans fats, reducing salt in processed foods, improving food labels to provide more information on added sugars and artificial dyes in processed foods, expanding the Nutrition North program, and introducing new restrictions on the commercial marketing of unhealthy foods and beverages to children. Further, Health Canada is working on the development of a new evidenced-based Food Guide. In order to achieve these priorities, funding of nutritional sciences to ensure evidenced-based data are available is critical. Failing to support nutrition research will mean that Canada will need to resort to data from other countries, some of which will not be relevant.

The CNS is the leading society integrating disciplines and professions interested in nutrition. We represent almost 600 professionals and trainees from across Canada. While the surveys were not exhaustive, the results clearly warrant concern by the nutrition community and CNS. There is an urgent need for high quality nutrition research and the nutrition community needs to be fully engaged in playing a direct role in the new CIHR Project and Foundation Scheme competition 
reforms being implemented. As a starting point, support your colleagues and the nutrition community by responding in the affirmative if your expertise is sought to review and to provide thoughtful feedback. The need for qualified, well-matched reviewers is essential to helping improve the quality of nutritional sciences in Canada.

CNS board members and senior nutrition research leaders met with Drs. Jane Aubin and Jeff Latimer from CIHR on September 29, 2016 to discuss our concerns. The discussions were productive and provided an opportunity to express our willingness to work collaboratively with CIHR to improve nutrition funding rates. It was noted that the nutrition community would be better served if 'nutrition' was more prominent in the descriptors used by CIHR to match grants to reviewers. Currently, the topic of Nutritional Health Sciences is considered a Level 2 Area of Science under Digestive, Endocrine and Excretory Systems in the descriptors list. CIHR invited CNS to help them develop modifications to their system to facilitate such changes. CIHR also invited applicants to update their grants by including nutrition or other specific keywords in the “descriptors" section.

There was also discussion about the need for increased overall funding to CIHR given that federal funding to CIHR has been flat-lined for the past eight years, not even keeping pace with inflation.

The meeting concluded with the following agreed upon next steps:

1. CNS would work with CIHR to enhance the visibility of nutritional sciences within the Project and Foundation application process by developing nutrition focused descriptors 
that are used in the matching process of applicants to reviewers. Additional information will be sent via the CNS to the nutrition community and posted on the CNS website on how to best enhance the success of your grant to be matched to an appropriate nutrition reviewer.

2. CNS will also be sending out a call for reviewers to be added to the CIHR database of reviewers.

3. CNS will support ongoing opportunities to advocate for increased research funding commitments, including the Canada's Fundamental Science Review led by the Minister of Science and chaired by Dr. David Naylor.

In conclusion, the rapidly changing research climate has created much uncertainty. However, through dialogue and engagement with CIHR there is an opportunity for positive change in the implementation of additional refinements to the new grant review system leading to greater success for the nutritional sciences in Canada. 